\title{
DIET OF Odorrana chapaensis (Bourret, 1937) FROM SON LA PROVINCE, VIETNAM
}

\author{
Pham Van Anh ${ }^{1, *}$, Nguyen Quang Truong ${ }^{2,3}$, Nguyen Van Hoang ${ }^{4}$ \\ ${ }^{1}$ Tay Bac University, Son La, Vietnam \\ ${ }^{2}$ Institute of Ecology and Biological Resources, VAST, Vietnam \\ ${ }^{3}$ Graduate University of Science and Technology, VAST, Vietnam \\ ${ }^{4}$ Hue Medical College, Thua Thien-Hue, Vietnam
}

Received 27 March 2019, accepted 28 May 2019

\begin{abstract}
Since there is currently a lack of data on the natural history of Odorrana chapaensis, an amphibian species listed in the IUCN Red List (2019), we herein provided the feeding ecology of this amphibian species is virtually lacking. We herein provide data about the diet of O. chapaensis based on the results of our field work in Ngoc Chien Commune, Muong La District and Xim Vang Commune, Bac Yen District, Son La Province, Vietnam. We used the stomach-flushing method to obtain the stomach contents of 85 individuals at two survey sites. A total of 20 prey categories with 334 items, comprising 299 items of invertebrates and 35 unidentified items, were found in the stomachs of $O$. chapaensis. The dominant prey items of $O$. chapaensis were Araneae, Polydesmida, insect larvae, Blattodea, Coleoptera, Dermaptera, Lepidoptera, Hymenoptera, and Orthoptera. The importance index for these categories ranged from $3.5 \%$ to $32.5 \%$. Coleoptera was the category with the highest frequency of prey items and its representatives were found in 45 stomaches.
\end{abstract}

Keywords: Odorrana chapaensis, food composition, prey items, stomach contents.

Citation: Pham Van Anh, Nguyen Quang Truong, Nguyen Van Hoang, 2019. Diet OF Odorrana chapaensis (Bourret, 1937) from Son La Province, Vietnam. Academia Journal of Biology, 41(3): 39-45. https://doi.org/10.15625/2615-9023/v41n3.13713.

*Corresponding author email: phamanh@utb.edu.vn

(C2019 Vietnam Academy of Science and Technology (VAST) 


\section{INTRODUCTION}

Odorrana chapaensis was originally described from northern Vietnam by Bourret (1937). The species was listed in the IUCN Red List (2018) as Near Threatened (van Dijk et al., 2004). Recently, this species was recorded for the first time from Son $\mathrm{La}$ Province (Ngo et al., 2016). In Vietnam, this species is currently known from Lao Cai, Son $\mathrm{La}$, and Ha Giang Provinces (Nguyen et al., 2009, Ngo et al., 2016). Elsewhere, this species has been reported from China (Yunnan) (Nguyen et al., 2009). Information on the feeding ecology of $O$. chapaensis is virtually lacking. In this study, we investigated the dietary ecology of $O$. chapaensis from Son La Province.

\section{MATERIALS AND METHODS}

Field surveys were conducted in Son La Province from 27 to 30 April 2015, from 15 to 17 April 2016, from 27 to 30 April 2016, from 7 to 10 October 2016, and from 26 to 30 April 2017 by A. V. Pham, N. B. Song, H. V. Tu, T. V. Dau, H. A. Giang, and Q. T. Bui in Ngoc Chien Commune $\left(21^{\circ} 21^{\prime} 46^{\prime \prime} \mathrm{N}, 103^{\circ} 30^{\prime} 38^{\prime \prime} \mathrm{E}\right.$, elevation: $1,780 \mathrm{~m})$, Muong La District and Xim Vang Commune $\left(21^{\circ} 36^{\prime} 378^{\prime \prime} \mathrm{N}\right.$, 104 ${ }^{\circ} 11$ '206'E, elevation: $\left.1,730 \mathrm{~m}\right)$, Bac Yen District, Son La Province (fig. 1).

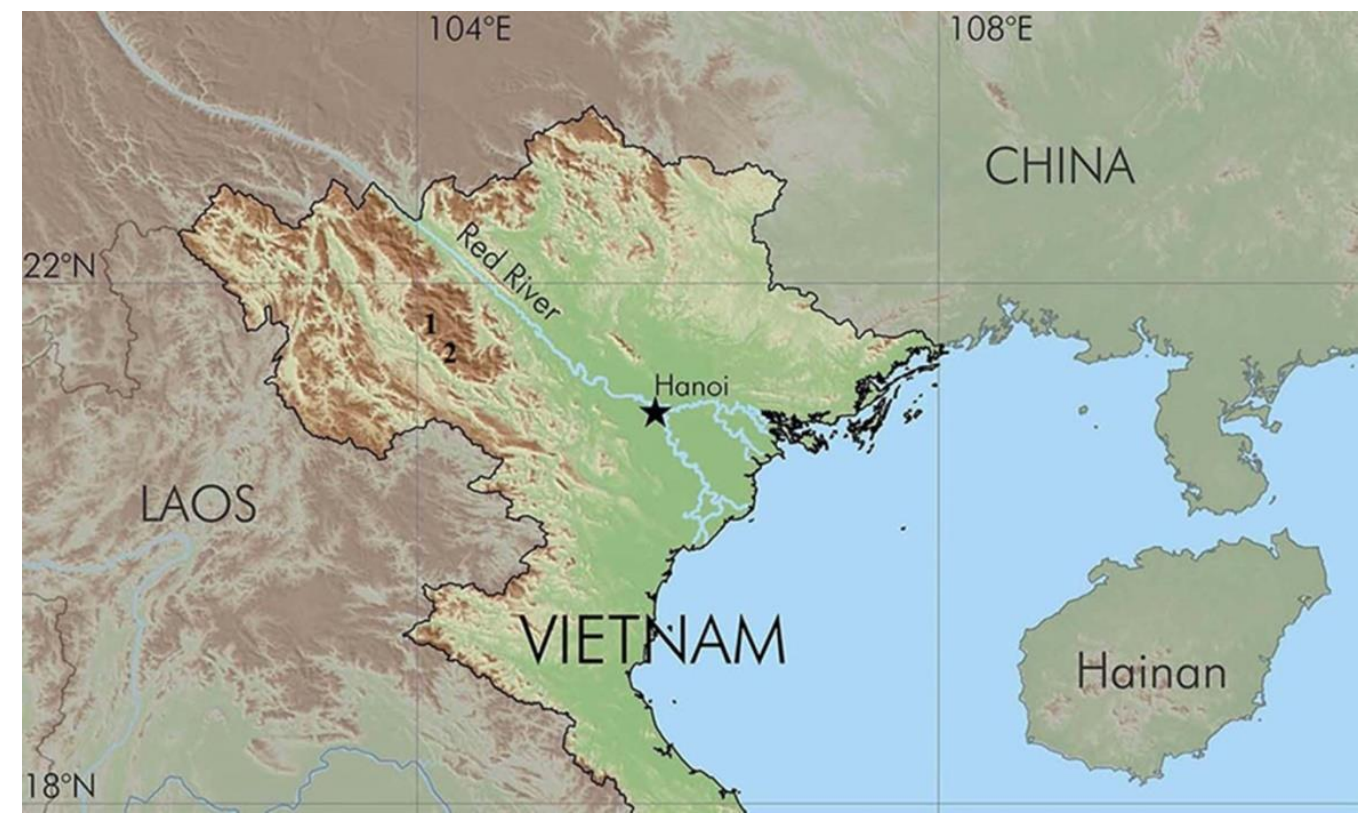

Figure 1. Map showing the survey sites in Son La Province: 1: Ngoc Chien; 2: Xim Vang

Specimens were collected by hand between 20:00 and 23:00. We measured snout-vent length (SVL) with a digital caliper to the nearest $0.1 \mathrm{~mm}$. Based on the size of captured animals, we divided individuals into two age groups: adults with SVL $>50 \mathrm{~mm}$ and subadults with SVL $\leq 50 \mathrm{~mm}$. We adopted stomach-flushing to obtain stomach contents without sacrificing frogs (Solé et al., 2005). Spatula, forceps, two syringes with thread $(60 \mathrm{ml})$, and the infusion tube of soft material (silicon) were used to collect prey items in the stomach of frogs, with special attention to avoid perforations of the oesophagus and stomach of small individuals. In addition, some other tools (i.e., sieve, small airtight vials, and vessel) and $70 \%$ ethanol were used for filtration, storage, to contain waste water, and to preserve items. Each amphibian received stomach-flushing only once following the guidelines approved by the American Society of Ichthyologists and Herpetologists for Animal Care (Beaupre et al., 2004). The water for flushing was taken 
from the streams where the frogs were captured and used after filtration. After flushing, frogs were monitored for the vital and body conditions and released within 30 min at the place of capture. Stomach samples were preserved in $70 \%$ ethanol for further analysis, and subsequently kept at the Department of Zoology, Faculty of Biology and Chemistry, Tay Bac University (TBU). For the taxonomic identification of frogs, we collected six voucher specimens for morphological analysis.

Prey items were identified under a microscope (Olympus SZ 700) based on identification keys (i.e., Csiro, 1991; Millar et al., 2000; Thai, 2003; Johnson \& Triplehorn, 2005). The maximum length (L) and width (W) of each prey item were measured to the nearest $0.01 \mathrm{~mm}$ using either a caliper or a calibrated ocular micrometer fitted to a microscope. The volume $(\mathrm{V})$ of prey items was calculated using the formula for a prolate spheroid ( $\pi=3.14$, Magnusson et al., 2003): $\mathrm{V}=4 \pi / 3 \times(\mathrm{L} / 2) \times(\mathrm{W} / 2)^{2}\left(\mathrm{~mm}^{3}\right)$. The index of relative importance (I) was used to determine the importance of each food category. This index provides a more informed estimation of food item consumption than any of the three components alone by using the following formula: IRI $=(\% \mathrm{~F}+\% \mathrm{~N}+\% \mathrm{~V}) / 3$ (Caldart et al., 2012), where $F$ is the frequency of stomachs that contain a particular food item and $\mathrm{N}$ is the total number of the food items in relation to all food items. We used the reciprocal Simpson's heterogeneity index, $1 / \mathrm{D}$, to calculate dietary heterogeneity: $\mathrm{D}=$ $\sum[\mathrm{ni}(\mathrm{ni}-1)] /[\mathrm{N}(\mathrm{N}-1)]$. Where ni is the number of food items in the $i$ th taxon category and $\mathrm{N}$ is the total number of prey categories (Krebs, 1999).

To estimate prey evenness, we used Shannon's index of evenness. Evenness is calculated from the equation: $\mathrm{J}^{\prime}=\mathrm{H}^{\prime} / \mathrm{Hmax}=$ $\mathrm{H}^{\prime} / \mathrm{ln} \mathrm{S}$. The maximum diversity (Hmax) that could possibly occur is that which would be found in a situation in which all taxa had equal abundance $\left(\mathrm{H}^{\prime}=\mathrm{Hmax}=\ln \mathrm{S}\right), \mathrm{S}$ is the total number of prey taxa, and $H^{\prime}$ is the
Shannon - Weiner index of taxon diversity. The value of $H^{\prime}$ is calculated from the equation: $\mathrm{H}^{\prime}=-\sum(\mathrm{Pi} \times \ln \mathrm{Pi})$, where the quantity $\mathrm{Pi}$ is the proportion of total food items belonging to the $i$ th taxon for the total food items of the sample (Magurran, 2004; Muñoz-Pedreros \& Merino, 2014).

Statistic analyses were performed with the SPSS 16.0 (SPSS Inc., Chicago, Illinois, USA) software and with the significance level set to $\mathrm{P}<0.05$ for all analyses. We used oneway analyses of variance (ANOVAs) to examine the number of prey items, frequency of occurrence, and prey volume collected among sex/age groups, localities, and months.

\section{RESULTS AND DISCUSSION}

A total of 85 stomachs of $O$. chapaensis from two sites in Son La Province were examined. Twelve of them (or 14.1\%) were empty. The numbers of stomachs for sex and age groups were 69 adults (29 males, 40 females) and 16 sub-adults. For localities, 57 were collected in Ngoc Chien and 28 in Xim Vang. For the time of collection, 66 were in April and 19 in October (table 1).

A total of 334 prey items (299 items of invertebrates and 35 unidentified items) belonging to 20 categories was found in the stomachs of $O$. chapaensis. The numbers of prey items in males were 1-12 (average 6.08 \pm 3.31 items) and $1-10$ in females (average $6.08 \pm 3.31$ items) and 1-8 in sub-adults (3.6 \pm 2.01 items). These values were significantly different (ANOVA; $F_{2,72}=4.81$; $P=0.011$ ) between adults and subadults. The numbers of food items in the specimens from Ngoc Chien ranged from 1 to $12(4.58 \pm$ 3.23 items) and those from Xim Vang ranged $1-10$ ( $4.56 \pm 2.63$ items $)$.

The numbers from the two sites were not significantly different from each other $\left(F_{1,72}=\right.$ $0.0001 ; P=0.98)$. The numbers of food items collected in April (4.54 \pm 3.07 items, ranging from 1 to 12$)$ and in October (4.71 \pm 2.97 items, ranging from 1 to 9 ) also were not significantly different from each other $\left(F_{1,72}=\right.$ $0.36 ; P=0.85)$. 
Table 1. Dietary composition of $O$. chapaensis in Son La Province: $\mathrm{F}=$ frequency of occurrence, $\mathrm{N}=$ number of items, $\mathrm{V}=$ volume $\left(\mathrm{mm}^{3}\right), \mathrm{Ix}=$ index of relative importance of each taxon $(n=73$ stomach contents)

\begin{tabular}{|l|c|c|c|c|c|c|c|}
\hline \multirow{2}{*}{ Prey category } & \multicolumn{2}{|c|}{ Frequency $(\mathrm{F})$} & \multicolumn{2}{c|}{ Count $(\mathrm{N})$} & \multicolumn{2}{c|}{ Volume $(\mathrm{V})$} & \multirow{2}{*}{$\mathrm{Ix}$} \\
\cline { 2 - 7 } & $\mathrm{F}$ & $\% \mathrm{~F}$ & $\mathrm{~N}$ & $\% \mathrm{~N}$ & $\mathrm{~V}$ & $\% \mathrm{~V}$ & \\
\hline Mollusca & 3 & 1.59 & 3 & 0.90 & 298.03 & 0.48 & 0.99 \\
\hline Opiliones & 3 & 1.59 & 3 & 0.90 & 72.68 & 0.12 & 0.87 \\
\hline Araneae & 11 & 5.82 & 12 & 3.59 & $1,065.84$ & 1.70 & 3.70 \\
\hline Polydesmida & 11 & 5.82 & 17 & 5.09 & 495.52 & 0.79 & 3.90 \\
\hline Blattodea & 9 & 4.76 & 9 & 2.69 & $10,340.80$ & 16.50 & 7.99 \\
\hline Coleoptera & 45 & 23.81 & 125 & 37.43 & $22,633.44$ & 36.12 & 32.45 \\
\hline Dermaptera & 9 & 4.76 & 11 & 3.29 & $1,632.64$ & 2.61 & 3.55 \\
\hline Diptera & 2 & 1.06 & 3 & 0.90 & 133.45 & 0.21 & 0.72 \\
\hline Ephemeroptera & 1 & 0.53 & 2 & 0.60 & 68.06 & 0.11 & 0.41 \\
\hline Phasmatodea & 1 & 0.53 & 1 & 0.30 & 778.46 & 1.24 & 0.69 \\
\hline Lepidoptera & 16 & 8.47 & 34 & 10.18 & $6,298.41$ & 10.05 & 9.57 \\
\hline Mantodea & 1 & 0.53 & 1 & 0.30 & $2,009.60$ & 3.21 & 1.35 \\
\hline Hymenoptera & 17 & 8.99 & 24 & 7.19 & $1,291.77$ & 2.06 & 6.08 \\
\hline Trichoptera & 2 & 1.06 & 9 & 2.69 & 814.63 & 1.30 & 1.68 \\
\hline Hemiptera & 4 & 2.12 & 5 & 1.50 & 353.14 & 0.56 & 1.39 \\
\hline Orthoptera & 11 & 5.82 & 13 & 3.89 & $7,298.51$ & 11.65 & 7.12 \\
\hline Plecoptera & 1 & 0.53 & 1 & 0.30 & 70.65 & 0.11 & 0.31 \\
\hline Isoptera & 3 & 1.59 & 3 & 0.90 & 69.36 & 0.11 & 0.87 \\
\hline Insecta larvae & 18 & 9.52 & 23 & 6.89 & $3,839.48$ & 6.13 & 7.51 \\
\hline Unidentified items & 21 & 11.11 & 35 & 10.48 & $3,091.35$ & 4.93 & 8.84 \\
\hline Total & 189 & 100.00 & 334 & 100.00 & $62,655.82$ & 100.00 & 100.00 \\
\hline
\end{tabular}

The mean number of food items per individual was $4.58 \pm 3.03$ (ranging from 1 to $12 ; \mathrm{n}=73$ ) and the mean volume per stomach was $858.3 \pm 1098.54 \mathrm{~mm}^{3}$ (ranging from 9.42 to $5091.51 \mathrm{~mm}^{3}$ ). Mean food item length was $11.52 \pm 7.75 \mathrm{~mm}$ (ranging from 1.0 to 60.0 $\mathrm{mm}, \mathrm{n}=334)$, mean food item width was 4.0 $\pm 2.34 \mathrm{~mm}$ (ranging from 0.2 to $14.0 \mathrm{~mm}, \mathrm{n}=$ 334 ), and mean volume per food item was $187.59 \pm 393.84 \mathrm{~mm}^{3}$ (ranging from 0.13 to $3,590.07 \mathrm{~mm}^{3}$ ).

We found 20 prey categories of invertebrates and only one category of unidentified items (table 1). The total dietary breadth of $O$. chapaensis from Northwest Vietnam was 0.18 (Simpson's index of diversity) and Shannon's evenness was 0.74 . Average food volumes of adult male individuals $\left(1414.92 \pm 42.55 \mathrm{~mm}^{3}\right.$, ranging from $42.55 \mathrm{~mm}^{3}$ to $5,091.51 \mathrm{~mm}^{3}$ ), adult female individuals $\left(840.65 \pm 840.65 \mathrm{~mm}^{3}\right.$, ranging from $16.75 \mathrm{~mm}^{3}$ to $3,215.56 \mathrm{~mm}^{3}$ ) and subadults $\left(87.77 \pm 55.93 \mathrm{~mm}^{3}\right.$, ranging from $9.4242 \mathrm{~mm}^{3}$ to $164.63 \mathrm{~mm}^{3}$ ) were significantly different (ANOVA; $F_{2.72}=6.36$; $P=0.03$; fig. 2) from each other.

The average volume of prey items per stomach from Ngoc Chien (1057.15 \pm $1244.42 \mathrm{~mm}^{3}$, ranging from $9.42 \mathrm{~mm}^{3}$ to $\left.5,091.51 \mathrm{~mm}^{3}\right)$ and from Xim Vang (426.02 \pm $463.8 \mathrm{~mm}^{3}$, ranging from $23.55 \mathrm{~mm}^{3}$ to 
$1,471.78 \mathrm{~mm}^{3}$ ) were significantly different from each other (ANOVA: $F_{1.72}=5.53 ; P<$ $0.02)$.

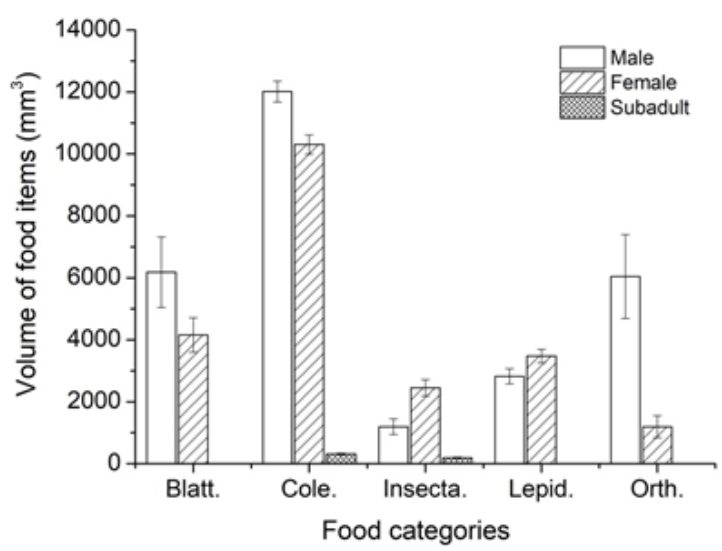

Figure 2. Volumes of major prey items (mean $\pm \mathrm{SD}$ ) of $O$. chapaensis from Son La Province: Cole $=$ Coleoptera; Derma $=$ Dermaptera; Insecta $=$ Insect larvae; Ort $=$ Orthoptera

The average volume of prey items per stomach in April $\left(845.25 \pm 1142.58 \mathrm{~mm}^{3}\right.$, ranging from $9.42 \mathrm{~mm}^{3}$ to $1,142.58 \mathrm{~mm}^{3}$ ) was not significantly different from the average prey volume per stomach in October $\left(913.28 \pm 924.79 \mathrm{~mm}^{3}\right.$, ranging from $42.55 \mathrm{~mm}^{3}$ to $3,215.55 \mathrm{~mm}^{3} ; F_{1.72}=$ $0.043 ; P<0.84)$.

The population of $O$. chapaensis from the Ngoc Chien area consumed the highest number of food categories with 20 types, while the population from Xim Vang area only consumed 11 food types. However, the largest dietary breadth was found in Xim Vang (6.41), with an evenness of 0.84. In contrast, the narrowest dietary breadth was found in Ngoc Chien (4.75) with an evenness of 0.70 (table 2).

The number of food categories in April (18 types) was more diverse than that in October (15 types). The largest dietary breadth was found in October (5.66), with an evenness of 0.70 , whereas the narrowest dietary breadth was found in April (4.99) with an evenness of 0.70 (table 2).

Table 2. Simpson's Index of Diversity and Shannon's Evenness among sex/age groups, sites, and month in the diet of $O$. chapaensis from Son La Province, Vietnam

\begin{tabular}{|l|c|c|}
\hline \multicolumn{1}{|c|}{ Contents } & Simpson's index $1 / D$ & Shannon's evenness $E$ \\
\hline Adult males & 5.29 & 0.77 \\
\hline Adult females & 5.55 & 0.77 \\
\hline Subadults & 6.56 & 0.87 \\
\hline Ngoc Chien & 4.75 & 0.70 \\
\hline Xim Vang & 6.41 & 0.84 \\
\hline April & 4.99 & 0.70 \\
\hline October & 5.66 & 0.70 \\
\hline Total & 39.21 & 5.35 \\
\hline
\end{tabular}

Adult males (17 prey categories) and females (16 prey categories) consumed more diverse prey than subadults (nine prey categories). However, the index of diversity of prey categories was higher in subadults $(6.56$ with an evenness index of 0.87 ) than in adult females (5.55 with an evenness index of 0.77) or adult males (5.29 with an evenness index of 0.77). Prey category richness from mid-curve points to late-curve points was higher for adult males and females than for subadults in both frequency (fig. 3a) and number of items (fig. 3b). 

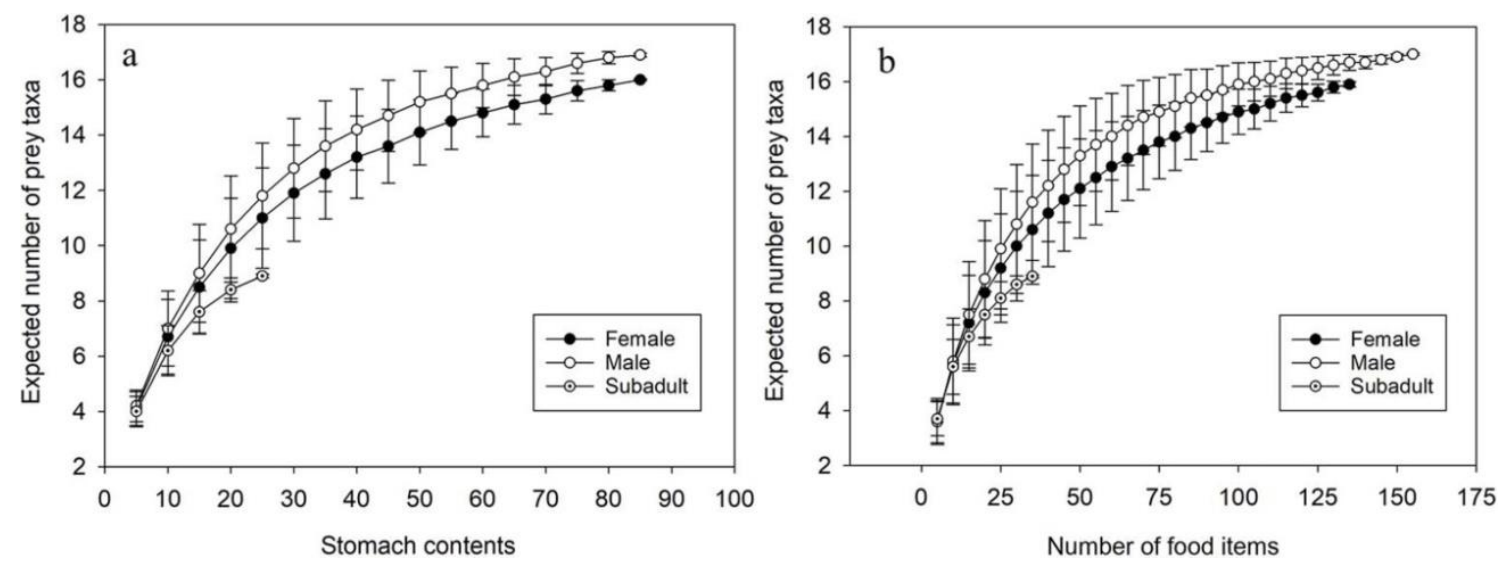

Figure 3. Expected prey-taxon accumulation curves from the data of (a) stomach contents and (b) counted food items consumed by $O$. chapaensis from Son La Province

\section{CONCLUSION}

A total of 20 prey categories with 334 items, comprising 299 items of invertebrates and 35 unidentified items, were found in the stomachs of $O$. chapaensis.

The dominant prey items of $O$. chapaensis were Araneae, Polydesmida, insect larvae, Blattodea, Coleoptera, Dermaptera, Lepidoptera, Hymenoptera, and Orthoptera, with importance indices ranging from $3.5 \%$ to $32.5 \%$. The category of Coleoptera had the highest frequency of prey items and was found in 45 stomachs.

Ngo et al. (2014) studied the dietary composition of Quasipaa verrucospinosa, another anuran species from Central Vietnam. The prey categories of this species were more diverse than those of $O$. chapaensis (27 vs. 20 in the latter). Interestingly, prey of $Q$. verrucospinosa comprised mainly invertebrates, but also fishes, frogs and conspecific subadults (see Ngo et al. 2014), which were not found in $O$. chapaensis from Son La Province in this study. Even so, the major prey items of $Q$. verrucospinosa were relatively similar to those of $O$. chapaensis, consisting of Araneae, Coleoptera, Hymenoptera, and Decapoda (Ngo et al. 2014).

Pham \& Nguyen (2018) recently reported the dietary composition of 23 prey categories of Nanorana yunnanensis from Son $\mathrm{La}$
Province. The major prey items of this frog species were Araneae, Coleoptera, Lepidoptera, Hemiptera, Orthoptera, and insect larvae. The food spectrum of $N$. yunnanensis slightly differed from that of $\mathrm{O}$. chapaensis in having prey items of Diplura, Crustacea and Amphibia (see Pham \& Nguyen, 2018).

Acknowledgements: We are grateful to the directorate of the Muong La Nature Reserve for the kind support for our field work. We thank Dau Van Trieu, Sung Ba Nenh and Bui The Quyen (Tay Bac University) for their assistance in the field. This research is supported by the Ministry of Education and Training (Grant No. B2019-TTB-562-13) to Pham Van Anh. Field equipment was donated by Idea Wild to Pham Van Anh.

\section{REFERENCES}

Beaupre S. J., Jacobson E. R., Lillywhite H. B., Zamudio K., 2004. Guidelines for Use of Live Amphibians and Reptiles in Field and Laboratory Research. The Herpetological Animal Care and Use Committee (HACC) of the American Society of Ichthyologists and Herpetologists: pp. 1-43.

Bourret R., 1937. Notes herpétologiques sur l'Indochine française. XIV. Les batraciens de la collection du Laboratoire des Sciences Naturelles de l'Université. 
Descriptions de quinze especes ou variétés nouvelles. Annexe au Bulletin Général de l'Instruction Publique: 5-56.

Caldart V. M., Iop S., Bertaso T. R. N., Zanini C., 2012. Feeding ecology of Crossodactylus schmidti (Anura: Hylodidae) in southern Brazil. Zoological Studies, 51(4): 484-493.

Csiro, 1991. The Insects of Australia. 2 Vols, Melbourne University Press, Carlton, Victoria.

IUCN, 2019: The IUCN Red list of Threatened Species, Version 2019.1. http://www.iucnredlist.org/ (accessed July 2019)

Johnson N. F., Triplehorn C. A., 2005. Borror and Delong's Introduction to the Study of Insects, Thomson Learning Inc., Belmont, California, USA.

Krebs C. J., 1999. Ecological Methodology, Addison Wesley Longman, Menlo Park, California, USA.

Magnusson W. E., Lima A. P., Silva W. A., Araújo M. C., 2003. Use of geometric forms to estimate volume of invertebrates in ecological studies of dietary overlap. Copeia, 1: 13-19.

Magurran A. E., 2004. Measuring Biological Diversity. Blackwell Science, Malden, Massachusetts, USA.

Millar I. M., Uys, V. M., Urban R. P., 2000. Collecand preserving Isectas and Arachnids, SDC, Switzerland.

Muñoz-Pedreros A., Merino C., 2014. Diversity of aquatic bird species in a wetland complex in southern Chile. Journal Journal of Natural History, 48, 1453 -1465. https://doi.org/10.1080/0022 2933.2013.867374
Ngo T. H., Le D. M., Pham T. C., Nguyen Q. T., 2016. Species diversity and phylogenetic relationships of the genus Odorrana (Amphibia: Anura: Ranidae) from northern Vietnam. Proceedings of the third National Scientific Workshop on Amphibians and Reptiles of Vietnam. Ha Noi, Vietnam: 67-76 (in Vietnamese).

Ngo V. B., Lee Y. F, Ngo D. C., 2014. Variation in dietary composition of granular spiny frogs (Quasipaa verrucospinosa) in central Vietnam. Herpetological Journal, 24(4): 245-253.

Nguyen V. S., Ho T. C., Nguyen Q. T., 2009. Herpetofauna of Vietnam, Edition Chimaira, Frankfurt am Main.

Pham V. A., Nguyen Q. T., 2018. Food spectrum of Nanorana yunnanensis (Anderson, 1879) from Son La Province. Journal of Vietnam National University Hanoi, 34(3): 10-16 [in Vietnamese]. https://doi.org/ 10.25073/25881140/vnunst.4747.

Solé M., Beckmann O., Pelz B., Kwet A., Egels W., 2005. Stomach-flushing for diet analysis in anuran: an improved protocol evaluated in a case study in Araucaria forests, southern Brazil. Studies on Neotropical Fauna and Environment, 40(1): 23-28.

Thai T. B., 2003. Invertebrates. Education Publishing House, Hanoi, Vietnam (in Vietnamese).

van Dijk P. P., Nguyen T. Q., Ohler A., Lu S. Q., Yang D. T., 2004. Odorrana chapaensis. The IUCN Red List of Threatened Species 2004: e.T58204A11746142. https://dx.doi.org/1 0.2305/IUCN.UK.2004.RLTS.T58204A1 1746142.en. 